\title{
Cost-effectiveness of combination therapy umeclidinium/vilanterol versus tiotropium in symptomatic COPD Spanish patients
}

This article was published in the following Dove Press journal: International Journal of COPD

18 January 2016

Number of times this article has been viewed

Marc Miravitlles'

Juan B Gáldiz ${ }^{2}$

Alicia Huerta ${ }^{3}$

Alba Villacampa ${ }^{4}$

David Carcedo ${ }^{4}$

Francisco Garcia-Rio ${ }^{5}$

'Pneumology Department, Hospital Universitari Vall d'Hebron, CIBER de Enfermedades Respiratorias (CIBERES), Barcelona, ${ }^{2}$ Pneumology Department, Hospital Universitario de Cruces, CIBER de Enfermedades Respiratorias (CIBERES), Bilbao, ${ }^{3}$ GlaxoSmithKline, Madrid, ${ }^{4}$ Oblikue Consulting, Barcelona, ${ }^{5}$ Pneumology Department, Hospital Universitario La Paz, IdiPAZ, Madrid, Spain
Correspondence: Marc Miravitlles Pneumology Department, Hospital Universitari Vall d'Hebron, Pg Vall d'Hebron II9-129, 08035 Barcelona, Spain Tel +34932746I57 Fax +34932746083 Email mmiravitlles@vhebron.net
Purpose: Umeclidinium/vilanterol (UMEC/VI) is a novel fixed dose combination of a long-acting muscarinic receptor antagonist (LAMA) and a long-acting beta 2 receptor antagonist (LABA) agent. This analysis evaluated the incremental cost-effectiveness ratio (ICER) of UMEC/VI compared with tiotropium (TIO), from the Spanish National Health System (NHS) perspective.

Methods: A previously published linked equations cohort model based on the epidemiological longitudinal study ECLIPSE (Evaluation of COPD Longitudinally to Identify Predictive Surrogate End-points) was used. Patients included were COPD patients with a post-bronchodilator forced expiratory volume in 1 second $\left(\mathrm{FEV}_{1}\right) \leq 70 \%$ and the presence of respiratory symptoms measured with the modified Medical Research Council dyspnea scale (modified Medical Research Council $\geq 2$ ). Treatment effect, expressed as change in $F E V$, from baseline, was estimated from a 24-week head-to-head phase III clinical trial comparing once-daily UMEC/VI with once-daily TIO and was assumed to last 52 weeks following treatment initiation (maximum duration of UMEC/VI clinical trials). Spanish utility values were derived from a published local observational study. Unitary health care costs $(€ 2015)$ were obtained from local sources. A 3-year time horizon was selected, and 3\% discount was applied to effects and costs. Results were expressed as cost/quality-adjusted life years (QALYs). Univariate and probabilistic sensitivity analysis (PSA) was performed.

Results: UMEC/VI produced additional 0.03 QALY and $€ 590$ vs TIO, leading to an ICER of $€ 21,475 / \mathrm{QALY}$. According to PSA, the probability of UMEC/VI being cost-effective was $80.3 \%$ at a willingness-to-pay of $€ 30,000 / \mathrm{QALY}$.

Conclusion: UMEC/VI could be considered as a cost-effective treatment alternative compared with TIO in symptomatic COPD patients from the Spanish NHS perspective.

Keywords: COPD, cost-effectiveness analysis, cost-utility analysis, umeclidinium/vilanterol, tiotropium

\section{Introduction}

COPD is a highly prevalent, chronic, progressive respiratory disease. In Spain, the EPISCAN study (the Epidemiologic Study of COPD in Spain) estimated a prevalence of $10.2 \%$ in people aged between 40 and 80 years. ${ }^{1}$ It is the fourth leading cause of death worldwide and is a major cause of chronic morbidity, above diseases such as diabetes or depression. ${ }^{2}$ Chronic, progressive dyspnea is one of the most prevalent symptoms of COPD, and it is estimated that approximately $50 \%$ of patients continue to have symptoms of dyspnea despite receiving treatment. ${ }^{3}$ The presence of dyspnea is associated with deterioration in the quality of life and increased mortality, regardless of exacerbations. ${ }^{4,5}$ 
In addition to the impact on the patient, COPD is also associated with a high consumption of health care resources and costs. In Spain, it is estimated that the annual mean health care cost of a COPD patient varies between $€ 1,388$ and $€ 2,154$, with the main components of cost being hospitalization (44\%) and drug treatment (41\%). ${ }^{6}$

The goal of COPD treatment is to reduce symptoms, reduce the frequency and severity of exacerbations, and improve the prognosis and quality of life of patients. ${ }^{7,8}$ Longacting bronchodilators, which improve lung function and reduce symptoms, are the basis of COPD maintenance drug therapy. ${ }^{7}$ There are two types of bronchodilators, long-acting $\beta 2$ receptor agonists (LABA) and long-acting muscarinic receptor antagonists (LAMA), which may be used alone or in combination. In patients with higher symptoms or in whom symptoms persist despite treatment, administration of an LAMA + LABA is recommended. . $^{7}$

Recently, the fixed-dose combination of the LAMA umeclidinium bromide (UMEC) and the LABA vilanterol (VI) (Anoro ${ }^{\circledR}$ Ellipta 55/22 $\mu$ g, GlaxoSmithKline SA, Brentford, United Kingdom) indicated as once-daily maintenance bronchodilator treatment to relieve symptoms in adults patients with $\mathrm{COPD}^{9}$ has been marketed in Spain, providing a new alternative treatment for symptomatic patients.

Due to the humanistic and economic burden associated with COPD, treatment decisions should be based on the analysis of the expected clinical and economic benefits. Health care resources allocation demands a rational principle and the consequent priority setting. An economic evaluation allows for a comparative analysis of alternative actions in terms of costs and health outcomes, being considered as a valuable tool for decision-making. Efficiency measured in economic evaluations is concerned with the relation between resource inputs (costs) and either intermediate outputs or final health outcomes. ${ }^{10}$

The aim of this study was to evaluate the cost-effectiveness of once-daily UMEC/VI vs the most-frequently used treatment, the LAMA tiotropium (TIO) $\left(\right.$ Spiriva $^{\circledR}$ Handihaler $18 \mu \mathrm{g}$, Boehringer Ingelheim SA, Ingelheim am Rhein, Germany), in symptomatic COPD patients from the perspective of the Spanish National Health System (NHS).

\section{Materials and methods}

The cost-effectiveness analysis was performed using a recently published validated model of COPD disease progression that allows comparing the long-term effects and costs of different treatment options. ${ }^{11}$ This model was adapted to the Spanish settings according to guidelines for health technology assessment in Spain and international recommendations. ${ }^{12,13}$ As no experimental or interventional research involving patients was applied, and no patient data was used, no ethical approval was required.

\section{Disease progression model description}

A qualitative conceptual model (CM) of COPD was developed to identify and describe qualitative causal relationships between disease attributes, progression, and outcomes. ${ }^{11}$ In order to do so, a literature review was performed to identify any prior published $\mathrm{CM}$ or literature reporting on the impact and association of COPD disease attributes. After critical analysis of the literature, a draft CM was developed based on the literature and expert opinion, and it was validated by a Delphi Panel. Delphi results were reviewed by a steering group of health economists, epidemiologists, and clinicians to determine the attributes, where sufficient evidence exists for use in economic modeling. ${ }^{11}$

Thus, the disease progression CM describes the associations between the demographic characteristics of patients, the central attributes of COPD representing disease progression (lung function, symptoms, exacerbations, and exercise tolerance), and their impact on health outcomes (expressed in terms of quality-adjusted life years [QALYs]) and costs.

Associations between the attributes and health outcomes were quantified by Exuzides et al using non-linear regression models of random effects, known as risk equations, which were developed from the longitudinal epidemiological ECLIPSE (Evaluation of COPD Longitudinally to Identify Predictive Surrogate End-points) study. ${ }^{14-16}$ Risk equations represent and quantify associations between the central indicators of the disease and their impact on HRQoL and mortality. Risk equations were estimated for each of the central attributes defined in the CM: exacerbations (moderate and severe), lung function (measured by forced expiratory volume in 1 second $\left.\left[\mathrm{FEV}_{1}\right]\right), \mathrm{COPD}$ symptoms (dyspnea, cough, and/or sputum), and exercise capacity (measured by 6-minute walk test distance [6MWD]) (equations available in Exuzides et $\mathrm{al}^{16}$ ). They were estimated to predict the effect of baseline and longitudinal covariates on the dependent central attribute, on an annual basis. Across the risk equations, the baseline variables used were age, CVD comorbidities, “Other" comorbidities, smoking status, sex, body mass index, 6MWD, fibrinogen level, modified Medical Research Council (mMRC) grade, St George's Respiratory Questionnaire (SGRQ) score, and prior exacerbations. The predicted outcomes of the risk equations of central attributes were used as inputs into the final outcome equations for HRQoL (measured by SGRQ score) and mortality. ${ }^{16}$ 
These risk equations were brought together to estimate the progression of COPD in terms of the central attributes of the disease through to final health outcomes of (quality adjusted) life expectancy, and health service cost. The model was therefore implemented as a linked-equation model. The model starts with baseline prognostic factors and moves on to predicting the central attributes (lung function, exacerbation rate, symptoms, and exercise capacity). The baseline variables and longitudinal central associations are then used together, to predict the final health outcomes of HRQoL utility and survival.

Internal validation compared 3 years of predicted cohort experience with results from ECLIPSE. At 3 years, the model predicted a survival rate, an annual exacerbation rate, and an annual decline in $\mathrm{FEV}_{1}$, which fell within the confidence limits of the ECLIPSE data.

For adaptation to Spain, a time horizon of 3 years was selected, in line with previously published analyses. ${ }^{17} \mathrm{~A}$ discount rate of $3 \%$ was applied for future costs and effects occurring after the first year based on local recommendations. ${ }^{12}$ The study was made from the perspective of the Spanish NHS, which only takes direct health care costs into account.

The results of the cost-effectiveness analysis were expressed using the incremental cost-effectiveness ratio (ICER) of UMEC/VI vs TIO, calculated using the formula:

$$
\mathrm{ICER}=\frac{\text { Cost }_{\mathrm{UMEC} / \mathrm{VI}}-\mathrm{Cost}_{\mathrm{TIO}}}{\mathrm{QALY}_{\mathrm{UMEC} / \mathrm{VI}}-\mathrm{QALY}_{\mathrm{TIO}}}
$$

\section{Compared options and study population}

The LAMA TIO was selected as the reference comparator as it is the most-widely used treatment in Spain. ${ }^{18}$

According to the recommendations on LAMA + LABA combination therapy, ${ }^{7,8}$ COPD patients with moderate or severe impairment in lung function (post-bronchodilator $\mathrm{FEV}_{1} \leq 70 \%$ of predicted normal values), with the presence of dyspnea ( $\mathrm{mMRC}$ score $\geq 2$ ) and a low risk of exacerbations were included. The remaining baseline characteristics of the patients with an impact on the estimated model results were defined using local studies and national statistics in order to be more representative of the Spanish population; ${ }^{19-21}$ in the cases where this was not possible, the best available published source was used (Table 1).

\section{Clinical entry data Effectiveness}

The disease progression model allows estimating differences between treatments in terms of lung function $\left(\mathrm{FEV}_{1}\right)$.
Table I Baseline characteristics of the population included in the analysis

\begin{tabular}{|c|c|c|}
\hline Baseline characteristics & Base case & Source \\
\hline \multicolumn{3}{|l|}{ Sex } \\
\hline Female (\%) & 17 & \multirow[t]{2}{*}{ Casanova et al ${ }^{19}$} \\
\hline Male (\%) & 83 & \\
\hline Mean age (years) & 67 & Casanova et $\mathrm{al}^{19}$ \\
\hline \multicolumn{3}{|l|}{ Body mass index } \\
\hline Low (\%) & 4.6 & \multirow[t]{3}{*}{ Casanova et al ${ }^{19}$} \\
\hline Medium (\%) & 60.3 & \\
\hline High (\%) & 35.1 & \\
\hline$\geq$ I cardiovascular comorbidity (\%) & 29 & \multirow{4}{*}{$\begin{array}{l}\text { Maleki-Yazdi } \\
\text { et } \mathrm{al}^{22}\end{array}$} \\
\hline$\geq$ I other comorbidity (\%) & 86 & \\
\hline History of exacerbations, $\geq$ I (\%) & 16.6 & \\
\hline mMRC score $\geq 2(\%)$ & 100 & \\
\hline Active smokers (\%) & 29 & Casanova et al ${ }^{19}$ \\
\hline \multirow[t]{2}{*}{ Height (m) (mean) } & 1.676 & Spanish National \\
\hline & & Health Survey ${ }^{21}$ \\
\hline \multirow[t]{2}{*}{ Fibrinogen $(\mu \mathrm{g} / \mathrm{mL})$ (mean) } & 458.8 & Vestbo et $\mathrm{al}^{14}$ \\
\hline & & Agusti et al ${ }^{15}$ \\
\hline $\begin{array}{l}\text { Number of exacerbations in } \\
\text { previous year (mean) }\end{array}$ & 0.27 & $\begin{array}{l}\text { Maleki-Yazdi } \\
\text { et al }{ }^{22}\end{array}$ \\
\hline Moderate/severe ratio & $80: 20$ & Hurst et a $\left.\right|^{44}$ \\
\hline SGRQ score (mean) & 42.7 & Almagro et $\mathrm{al}^{20}$ \\
\hline $\begin{array}{l}\text { Post-bronchodilator baseline FEV, } \\
\text { (\%pred) (mean) }\end{array}$ & $46.4 \%$ & $\begin{array}{l}\text { Maleki-Yazdi } \\
\text { et al }{ }^{22}\end{array}$ \\
\hline $\begin{array}{l}\text { Six-minute walk test (6MWT) }(m) \\
\text { (mean) }\end{array}$ & 438 & Casanova et al ${ }^{19}$ \\
\hline
\end{tabular}

Abbreviations: mMRC, modified Medical Research Council; SGRQ, St George's Respiratory Questionnaire; $\mathrm{FEV}_{1}$, forced expiratory volume in I second.

Differences between UMEC/VI and TIO were determined according to the results of the 24-week phase III clinical trial that compared the efficacy of UMEC/VI and TIO in terms of trough $\mathrm{FEV}_{1}{ }^{22}$ This clinical trial was a multicenter, randomized, blinded, double-dummy, parallel-group study that randomized 905 patients aged $>40$ years with moderate-to-very severe COPD and an established clinical history of COPD (defined by American Thoracic Society/European Respiratory Society guidelines). This study found an increase in trough $\mathrm{FEV}_{1}$ of $112 \mathrm{~mL}$ for UMEC/VI 55/22 $\mu \mathrm{g}$ compared with TIO $18 \mu \mathrm{g}$ at 24 weeks of treatment. This difference in efficacy between treatments was applied during the first year of the time horizon, according to the study by Donohue et al, ${ }^{23}$ which showed the sustained effect of UMEC/VI on lung function at 52 weeks. As there is no published data for UMEC/VI beyond 52 weeks, a conservative scenario that assumed no difference in efficacy between the two treatments beyond that time was used.

\section{Utilities}

In the initial disease progression model, ${ }^{11,16}$ quality of life was obtained using an adjusted risk equation constructed using the SGRQ scores reported in the ECLIPSE study, and 
subsequently converted to utilities according to the algorithm of Starkie et al. ${ }^{24}$

In this analysis, for better adaptation to the Spanish environment, a new risk equation estimated utility values according to specific data on Spanish COPD patients obtained from an observational study that estimated utility scores in these patients. ${ }^{25,26}$ In this study, utility values were derived from the preference-based generic questionnaire EQ-5D-3L, applying weighted Spanish societal preferences, obtained from a multicenter, observational, cross-sectional study that included patients aged $\geq 40$ years, with spirometrically confirmed COPD. The new risk equation was a saturated linear regression model explained by the variables from the observational study, which were considered to have an impact on both utility and the disease progression model (explanatory variables). These variables were sex, age, body mass index, comorbidities, smoking status, lung function, exacerbation history, symptoms measured by mMRC score, and the presence of cough and sputum (Table 2). All these variables were obtained directly from the local study except cough and sputum, which was assumed to correspond to a score of $\geq 3$ in the first two dimensions of the COPD Assessment Test questionnaire collected in the local study.

\section{Economic entry data}

Costs were counted according to the number of exacerbations (moderate to severe), the costs of follow-up according to the frequency of dyspnea symptoms, and the cost of drug treatment. All costs were estimated in euros 2015 and were adapted from Spanish sources.

Table 2 Risk equation to incorporate Spanish utilities (linear regression model)

\begin{tabular}{lc}
\hline Variables & Effect \\
\hline Intercept & 0.8345 \\
Female (vs male) & -0.0875 \\
Low BMI (vs mean) & -0.0059 \\
High BMI (vs mean) & -0.0136 \\
Cardiovascular comorbidities (vs no) & -0.0074 \\
Other comorbidities (vs no) & -0.0074 \\
Smoker (vs ex-smoker) & -0.0244 \\
Age & 0.0012 \\
Number of exacerbations & -0.029 I \\
Post-bronchodilator FEV (\%pred) & 0.0006 \\
mMRC 2-3 (vs 0-I) & $-0.154 \mathrm{I}$ \\
mMRC 4 (vs 0-I) & -0.5326 \\
Cough and sputum (vs no) ${ }^{\mathrm{a}}$ & -0.0672 \\
\hline
\end{tabular}

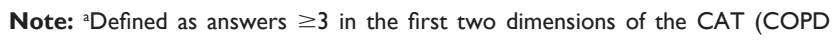
Assessment Test) questionnaire.

Abbreviations: $\mathrm{BMI}$, body mass index; $\mathrm{FEV}_{1}$, forced expiratory volume in I second; pred, predicted; mMRC, modified Medical Research Council.
The pharmacologic costs associated with UMEC/VI and TIO were expressed in terms of the retail price plus value added tax (PTP+VAT) ${ }^{27}$ and were counted as the cost/day during the 3-year time horizon of the analysis.

To calculate the cost of exacerbations, a moderate exacerbation was defined as one requiring treatment with oral corticosteroids and/or antibiotics and a severe exacerbation as one requiring hospitalization. The costs associated with each episode were estimated from the resource use specified in the studies by Miravitlles et al, ${ }^{28,29}$ resulting in a cost of $€ 70.86$ for moderate exacerbations (considering drug costs, one visit to primary care, and one visit to emergency department for $4.3 \%$ of the patients), and $€ 4,349.61$ for severe exacerbations (considering one visit to primary care, one visit to emergency department, and 8 days of hospitalization).

There are no reported data on the annual cost associated with patient follow-up according to the frequency of dyspnea, although one UK study has estimated the costs of follow-up according to the severity of dyspnea measured by the $\mathrm{mMRC}$ score. ${ }^{30}$ For this reason, the following assumption of equivalence between the frequency of the symptoms of dyspnea and their severity was made:

- Level 1: No symptoms per week $=$ mMRC 0-1

- Level 2: Symptoms several days per week $=$ mMRC 2-3

- Level 3: Symptoms almost daily $=$ mMRC 4

Using this assumption, the annual cost for each level was calculated based on the annual cost of following a COPD patient in Spain, ${ }^{31}$ the distribution of the severity of dyspnea in Spain, ${ }^{19}$ and the distribution of costs in the study by Punekar et al (Table 3). ${ }^{30}$

Table 3 Unitary costs of health care resources included in the analysis

\begin{tabular}{|c|c|c|}
\hline Type & Cost $(€)$ & Source \\
\hline \multicolumn{3}{|l|}{ Drug cost (PTP + VAT) } \\
\hline $\begin{array}{l}\text { UMEC/VI - 55/22 umeclidinium/ } \\
\text { vilanterol powder for inhalation } 30 \text { doses }\end{array}$ & 70.25 & $\begin{array}{l}\text { National } \\
\text { Formulary }\end{array}$ \\
\hline $\begin{array}{l}\text { TIO - } 18 \mu \text { g tiotropium powder for } \\
\text { inhalation } 30 \text { capsules }\end{array}$ & 49.06 & Listing $^{27}$ \\
\hline \multicolumn{3}{|l|}{ Cost per episode of exacerbation } \\
\hline Moderate exacerbation & 70.86 & Miravitlles \\
\hline Severe exacerbation & $4,349.61$ & et $\mathrm{al}^{28,29}$ \\
\hline \multicolumn{3}{|c|}{ Annual cost of management according to symptoms } \\
\hline $\begin{array}{l}\text { Dyspnea level I: no symptoms per } \\
\text { week }=\text { mMRC 0-I }\end{array}$ & 511.18 & $\begin{array}{l}\text { Punekar } \\
\text { et al }\left.\right|^{30}\end{array}$ \\
\hline $\begin{array}{l}\text { Dyspnea stage } 2 \text { : symptoms several days } \\
\text { per week }=\text { mMRC } 2-3\end{array}$ & 681.72 & $\begin{array}{l}\text { Almagro } \\
\text { et } \mathrm{al}^{20}\end{array}$ \\
\hline $\begin{array}{l}\text { Dyspnea level } 3 \text { : symptoms nearly every } \\
\text { day }=\text { mMRC } 4\end{array}$ & 901.7 & $\begin{array}{l}\text { Sicras } \\
\text { et a }\left.\right|^{31}\end{array}$ \\
\hline
\end{tabular}

Abbreviations: PTP + VAT, retail price plus value added tax; UMEC/VI, umeclidinium and vilanterol; TIO, tiotropium; mMRC, modified Medical Research Council. 
Table 4 Deterministic sensitivity analysis values

\begin{tabular}{|c|c|c|}
\hline Parameter & Base case & Alternative values \\
\hline Time horizon & 3 years & 1 year, 5 years \\
\hline Baseline characteristics & $\begin{array}{l}\text { Spanish population data, clinical } \\
\text { development of UMEC/VI and ECLIPSE }\end{array}$ & $\begin{array}{l}\text { Clinical development UMECI } \\
\mathrm{VI} \text { and ECLIPSE }\end{array}$ \\
\hline Efficacy data UMEC/VI vs TIO & $\begin{array}{l}\text { I I } 2 \mathrm{~mL}(8 \mathrm{I} .144 ; P<0.00 \mathrm{I}) \\
\left(\text { Maleki-Yazdi et al }{ }^{22}\right)\end{array}$ & $\begin{array}{l}60 \mathrm{~mL}(10.109 ; P=0.018) \\
\left(\text { Decramer et } \mathrm{al}^{33}\right)\end{array}$ \\
\hline Duration of efficacy & First year & $\begin{array}{l}\text { First } 6 \text { months } \\
\text { Entire time horizon ( } 3 \text { years) }\end{array}$ \\
\hline Modeling of quality of life & Spanish utilities (MI) & SGRQ \\
\hline Discount rate for costs and future events & $3 \%$ & $(0 \%-5 \%)$ \\
\hline Exacerbation unitary cost (moderate and severe) & Estimated from Miravitlles et $\mathrm{al}^{28,29}$ & $( \pm 20 \%)$ \\
\hline Follow-up cost according dyspnea levels (three & Estimated from Sicras et al ${ }^{31}$ & $( \pm 20 \%)$ \\
\hline levels of frequency) & Punekar et a $\left.\right|^{30}$ & \\
\hline
\end{tabular}

Abbreviations: UMEC/VI, umeclidinium and vilanterol; TIO, tiotropium; SGRQ, St George's Respiratory Questionnaire; ECLIPSE, Evaluation of COPD Longitudinally to Identify Predictive Surrogate End-points.

\section{Uncertainty analysis}

Deterministic and probabilistic sensitivity analyses were performed to evaluate the uncertainty of some parameters in the model results and to determine the robustness of the results.

In the deterministic sensitivity analyses, the influence of various parameters on the results of the model was estimated by individual modification. Table 4 shows the modified parameters and the new values used. In addition, to evaluate the uncertainty associated with the development of the new risk equation to obtain utilities, alternative equations were adjusted as shown in Tables S1-S3.

In the probabilistic sensitivity analysis (PSA) 10,000 simulations were performed using Monte Carlo methodology ${ }^{32}$ simultaneously modifying the coefficients of all risk equations (Cholesky decomposition was considered to maintain correlation effects), the baseline characteristics (beta and normal distributions) of the patients, and the difference in efficacy between treatments (normal distribution).

All model calculations were made using Microsoft Excel 2010.

\section{Results}

\section{Base case}

The results of the cost-effectiveness analysis of UMEC/VI vs TIO after 3 years of treatment are summarized in Table 5.

Table 5 Results of base case

\begin{tabular}{lll}
\hline & UMEC/VI & TIO \\
\hline Health outcomes (QALY) & 2.025 & 1.998 \\
Costs & $€ 6,215$ & $€ 5,625$ \\
ICER (€/QALY) & & $€ 21,475$ \\
\hline
\end{tabular}

Abbreviations: UMEC/VI, umeclidinium and vilanterol; TIO, tiotropium; ICER, incremental cost-effectiveness ratio; QALY, quality-adjusted life year.
Compared with $\mathrm{TIO}$, the improvement in lung function observed with UMEC/VI resulted in an increase of 0.03 QALY. UMEC/VI treatment resulted in additional costs of $€ 590$, mainly due to the difference in the cost of drug treatment. This resulted in an ICER of $€ 21,475 / \mathrm{Q} A L Y$.

\section{Uncertainty analysis}

The tornado diagram (Figure 1) shows the results of the deterministic sensitivity analysis described in Table 5. The ICER ranges between $€ 20,636$ and $€ 47,428$. The parameters with the greatest impact were the modification of the utility values (ICER increases if the initial equation based on the ECLIPSE study is used), the difference in efficacy between treatments (ICER increases with a decreased difference in efficacy based on Decramer et al, ${ }^{33}$ the duration of the effect (ICER decreases with increasing duration), and the time horizon considered (ICER decreases with decreasing time horizon). The other parameters considered produced no changes in the ICER.

Figure 2 shows the cost-effectiveness plane with the results of the PSA: $99.9 \%$ of the simulations are located in the first quadrant, representing a higher cost and greater effectiveness of UMEC/VI vs TIO. Figure 3 shows the acceptability curve of the probability that UMEC/VI is costeffective compared with TIO, the probability increases as the willingness to pay per QALY gained rises.

\section{Discussion}

In today's health care environment, decision-making must be based not only on criteria of efficacy and safety, but also on those of efficiency. Cost-effectiveness analyses provide information on the economic value of a health intervention, 


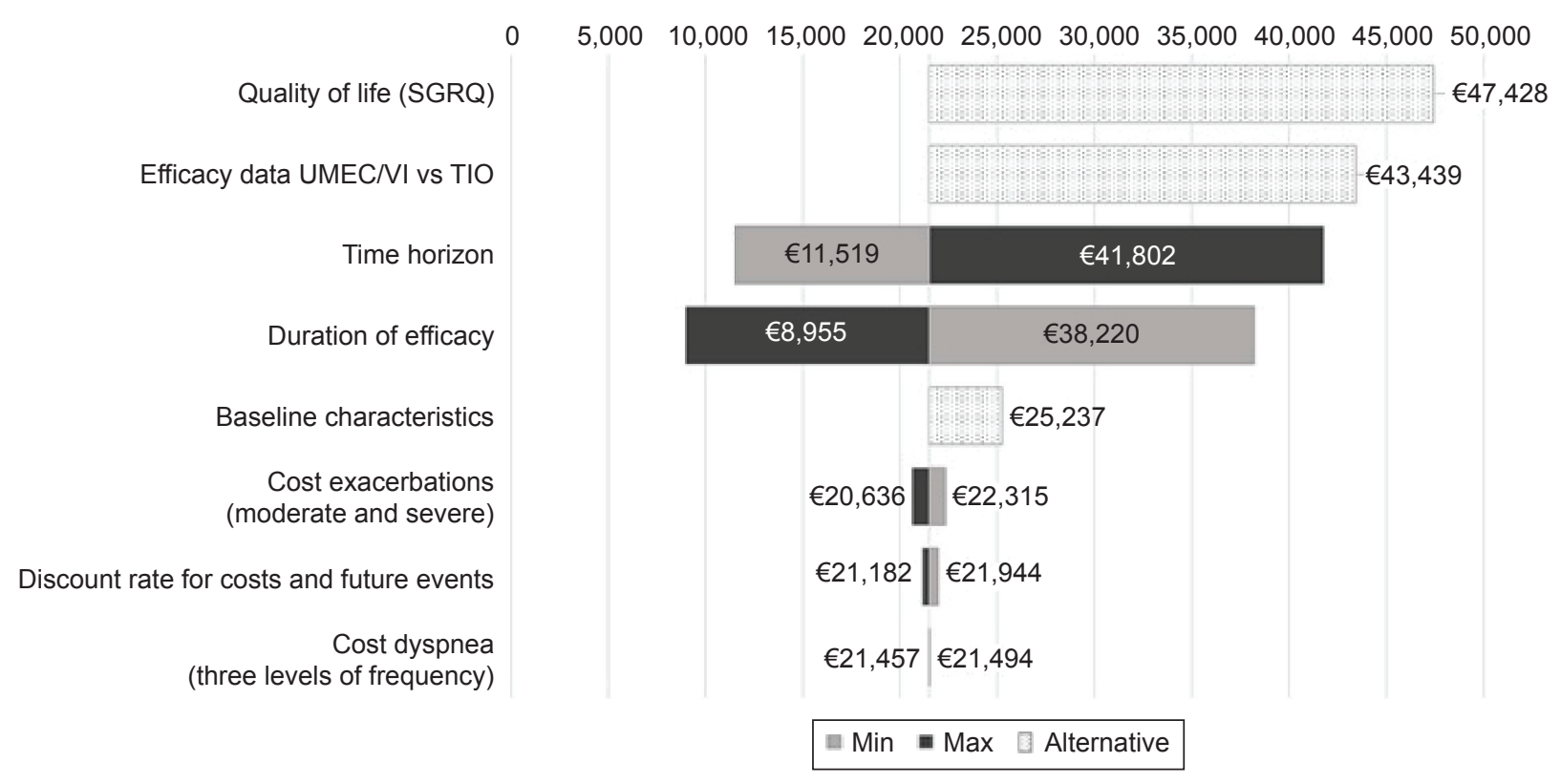

Figure I Results of the sensitivity analysis.

Abbreviations: SGRQ, St George's Respiratory Questionnaire; UMEC/VI, umeclidinium and vilanterol; TIO, tiotropium; Min, minimum; Max, maximum.

generally in comparison with the mostfrequently used intervention. Thus, cost-effectiveness analyses are tools that may aid health care managers and decision makers make informed decisions. This analysis studied the economic value to the NHS of a new treatment, the combination of UMEC/VI vs TIO, the most widely used treatment for COPD in Spanish clinical practice. ${ }^{18}$

In the base case, the ICER of UMEC/VI is $€ 21,475 /$ QALY compared with TIO, suggesting that UMEC/VI may be considered as a cost-effective option vs TIO, as the ICER is below the threshold of $€ 30,000 / \mathrm{QALY}$ generally accepted in Spain. ${ }^{34,35}$ In the PSA, UMEC/VI was a cost-effective option vs TIO in $80.3 \%$ of the simulations using the same threshold.

The QALY quantifies changes in utility over the life of the patient, and it has two components; quality and quantity of life, being the most accepted health-related utility measure. In the model developed, QALY difference observed between compared treatments was a consequence of different cumulative number of exacerbations over the time horizon analyzed, 6MWT results, percentage of patients with symptoms (dyspnea and cough and sputum), quality of life, and survival.

Various international and Spanish economic evaluations of COPD have been made..$^{17,36-39}$ The efficiency of TIO has

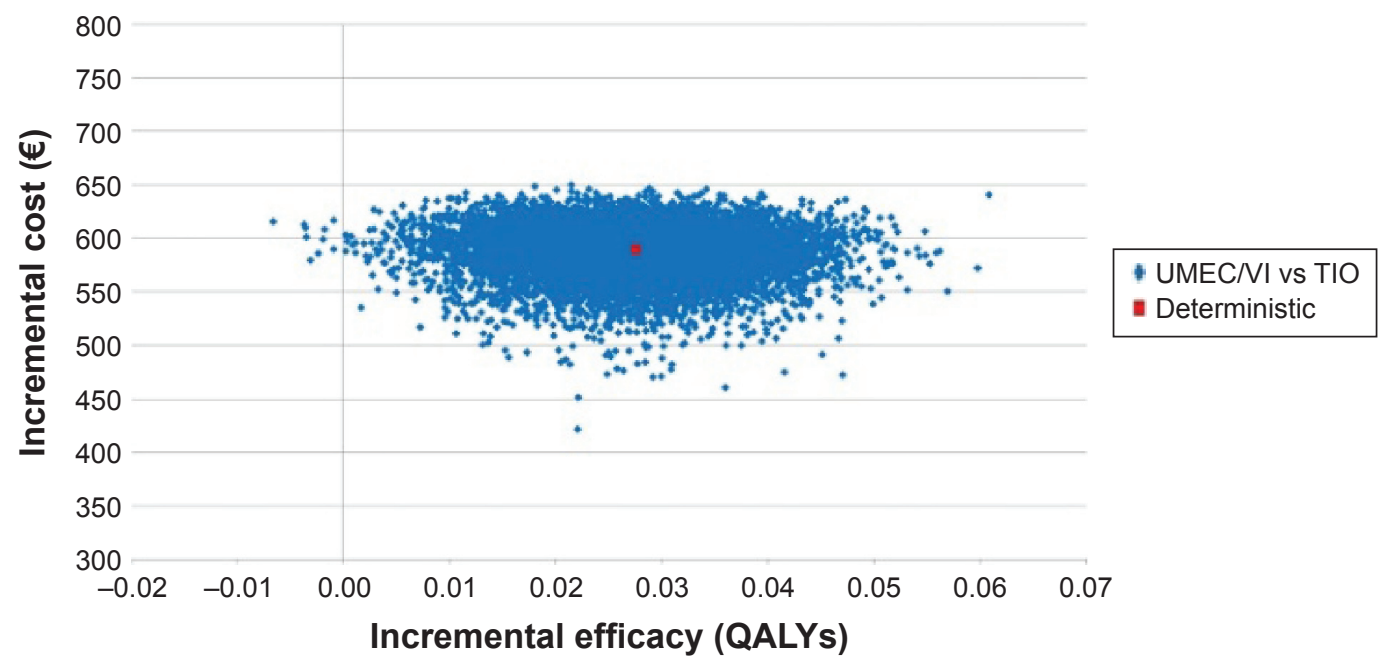

Figure 2 Probabilistic sensitivity analysis results. Cost-effectiveness plane.

Abbreviations: QALYs, quality-adjusted life years; UMEC/VI, umeclidinium and vilanterol; TIO, tiotropium. 


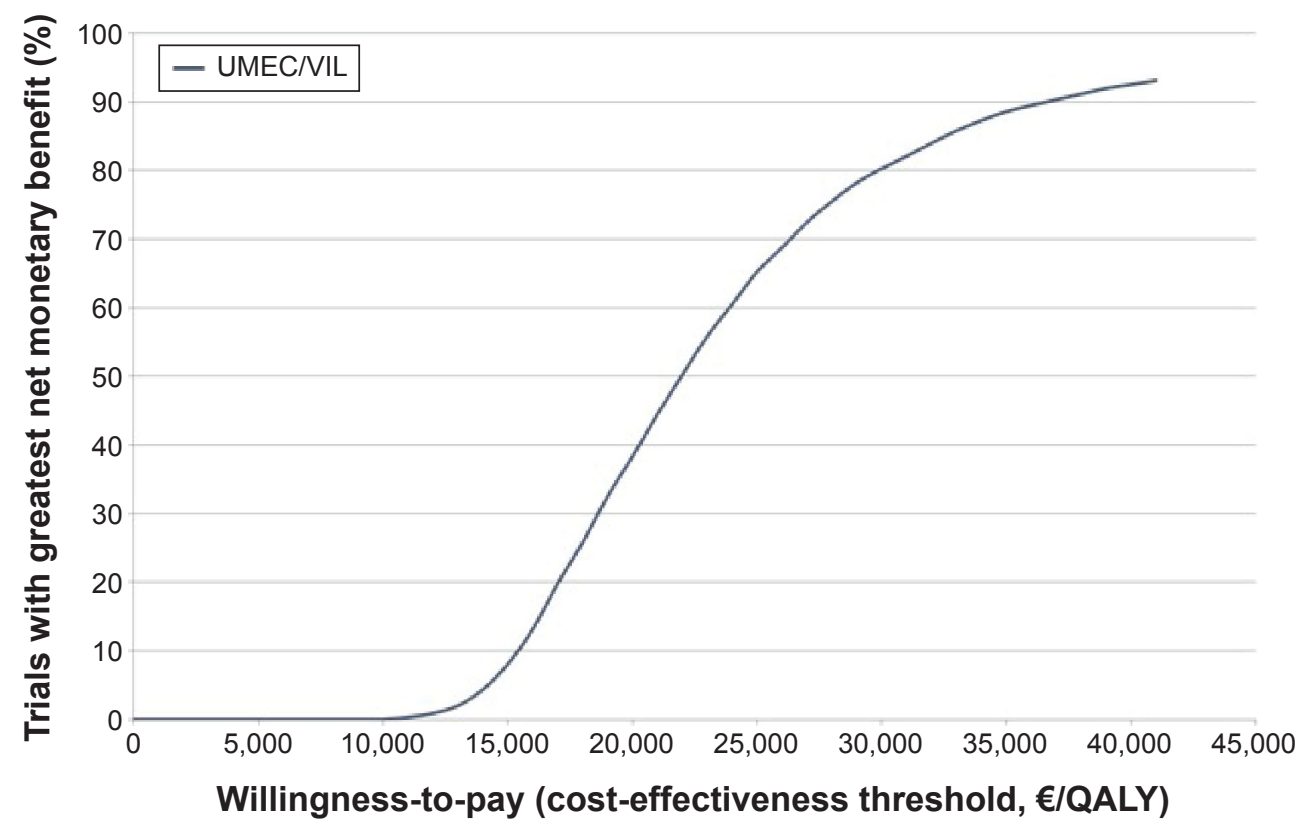

Figure 3 Acceptability curve.

Abbreviations: QALY, quality-adjusted life year; UMEC/VIL, umeclidinium/vilanterol.

been evaluated in several studies, ${ }^{36-38}$ which have found it is a cost-effective treatment compared with other bronchodilators, such as ipratropium or salmeterol. When comparing the present analysis with those already published, it can be concluded that both methods, population, outcomes, and costs included are similar with the considered ones in the model here explained. ${ }^{17}$

The present analysis is the first to determine the costeffectiveness of the combination of two bronchodilators compared with monotherapy in the Spanish setting. The same analysis has been carried out in the UK with similar results, showing that UMEC/VI has a high probability of being cost effective vs TIO at $£ 30,000 / \mathrm{QALY}^{40}$ Recently, a cost-effectiveness analysis of combined treatment with indacaterol + glycopyrronium from the perspective of the Swedish NHS has been published. ${ }^{41}$ Although in this study the comparators used were a free combination or the combination of an inhaled corticosteroid + LABA, the results support the efficient use of LAMA + LABA treatment in symptomatic patients.

Model selection is a critical factor in cost-effectiveness analyses, since the model must accurately represent the disease studied. Generally, the models used in COPD are based exclusively on pulmonary function as the basis for the transition between different health states. ${ }^{17}$ The present analysis used a previously published model of disease progression ${ }^{11}$ that incorporates exacerbations, symptoms, and exercise capacity as measures of the progression of COPD. This wider focus on the progression of COPD is in line with the latest definitions of the disease based on a multidimensional assessment that goes beyond lung function., ${ }^{7,8}$

The population included in the analysis was symptomatic COPD patients with moderate-to-very severe FEV impairment but with low risk of exacerbations. The use of LAMA + LABA combination treatment is recommended in patients with higher symptoms or in whom symptoms or obvious limitations in exercise persist despite receiving monotherapy. ${ }^{7,8}$ The results obtained here support this recommendation, with UMEC/VI being an efficient treatment option compared with monotherapy with TIO.

The development of a new risk equation to incorporate Spanish utilities has various positive points. First, it allows better adaptation to the Spanish setting and makes the results more robust, being the first published Spanish analysis that incorporates utility values of Spanish COPD patients. In addition, in the initial disease progression model, utility was obtained by mapping of the SGRQ; although this technique is useful and commonly used, using utility scores obtained directly from generic patient questionnaires is recommended whenever possible. ${ }^{25}$ The study used to obtain utilities ${ }^{25,26}$ did not collect the same variables as those included in the initial equation of the disease progression model. This might be considered as a limitation, but the new risk equation included all available relevant variables, and therefore provides the best explanation of the variance in utility observed in Spanish patients. To evaluate 
the uncertainty of including Spanish utilities, sensitivity analysis with alternative equations for obtaining utilities was made. The results obtained, shown in Table S3, were very similar, except for the M2 equation that did not take into account the effect of lung function and therefore could not distinguish effects between treatments. With respect to the initial risk equation based on the SGRQ, variations in $\mathrm{FEV}_{1}$ showed less direct impact on utility.

Despite the advantages identified, the analysis had some limitations. First, the time horizon used and the limitations of long-term extrapolations from studies of limited duration should be taken into account, particularly with respect to the duration of the effect on the improvement in lung function observed in clinical trials. Some models with a lifetime horizon assume that the benefits in lung function observed at the beginning of treatment are maintained over time. ${ }^{17,42}$ Although some studies indicate that improvements in lung function may last up to 3 years, ${ }^{43}$ this benefit has not been demonstrated in long-term studies. Therefore, most reported cost-effectiveness analyses ${ }^{17}$ use a time horizon between 1 and 3 years, maintaining the treatment effect during this time. In the present analysis, a time horizon of 3 years was selected, and a more conservative strategy was adopted in which difference in efficacy between treatments was maintained for only the first 12 months, which corresponds to the maximum duration of studies of UMEC/VI, while the costs associated with pharmacological treatment were maintained for 3 years.

Another limitation of economic evaluations is related to the quality of data. In this case, local Spanish data sources were used when available or, in their absence, the best available evidence. All assumptions were validated by the authors, and a sensitivity analysis was made to evaluate uncertainty.

\section{Conclusion}

The results of this cost-effectiveness analysis show that treatment with UMEC/VI in symptomatic COPD patients is a cost-effective option compared with TIO from the perspective of Spanish NHS, as the ICER was below the threshold commonly accepted in Spain to consider interventions as efficient.

\section{Acknowledgments}

The authors thank Carles Forné for his contribution to the development of the risk equation for incorporation Spanish utilities, and Yogesh Punekar for his contribution to the development of the analysis and his comments on earlier versions of this manuscript. This analysis was funded by GlaxoSmithKline (protocol code HO-14-15747).

\section{Author contributions}

M Miravitlles participated, as a leading investigator, in the design of the study, model adaptation, contributed to the review of the results and its discussion, and participated actively in the manuscript review. JB Gáldiz and F GarciaRio participated as an expert panel adapting the model inputs, reviewing the manuscript and discussing the results contributing with fruitful comments. A Huerta Hernandez, D Carcedo Rodriguez, and A Villacampa Lordan designed the study, reviewed the literature, adapted the model, and wrote the first draft of the manuscript. All authors contributed toward data analysis, drafting and revising the paper and agree to be accountable for all aspects of the work.

\section{Disclosure}

M Miravitlles has received speaker fees from Almirall, Boehringer Ingelheim, Pfizer, AstraZeneca, Chiesi, GlaxoSmithKline, Menarini, Grifols, and Novartis, and consulting fees from Almirall, Boehringer Ingelheim, Pfizer, GlaxoSmithKline, Gebro Pharma, CLS Behring, Cipla, MediImmune, Takeda, Novartis, and Grifols. JB Gáldiz has received speaker fees from Almirall, Boehringer Ingelheim, Pfizer, AstraZeneca, GlaxoSmithKline, Menarini, Grifols, and Novartis. F Garcia-Rio has received speaker fees from Boehringer Ingelheim, Pfizer, Chiesi, GlaxoSmithKline, Menarini, MundiPharma, Novartis, and Rovi, and consulting fees from Boehringer Ingelheim, Pfizer, GlaxoSmithKline, and Novartis. A Huerta Hernandez is employed by and holds stocks of GlaxoSmithKline. A Villacampa Lordan and D Carcedo are employees of Oblikue Consulting, an independent consulting firm who received funding to carry out this analysis.

\section{References}

1. Miravitlles M, Soriano JB, Garcia-Rio R, et al. Prevalence of COPD in Spain: impact of undiagnosed COPD on quality of life and daily life activities. Thorax. 2009;64(10):863-868.

2. Murray CJ, Vos T, Lozano R, et al. Disability-adjusted life years (DALYs) for 291 diseases and injuries in 21 regions, 1990-2010: a systematic analysis for the Global Burden of Disease Study 2010. Lancet. 2012;380(9859):2197-2223.

3. Dransfield MT, Bailey W, Crater G, Emmett A, O'Dell DM, Yawn B. Disease severity and symptoms among patients receiving monotherapy for COPD. Prim Care Respir J. 2011;20(1):46-53.

4. Nishimura K, Izumi J, Tsukina M, Oga J. Dyspnea is a better predictor of 5-year survival than airway obstruction in patients with COPD. Chest. 2002;121(5):1434-1440.

5. Burgel PR, Escamilla R, Perez T, et al. Impact of comorbidities on COPD-specific health related quality of life. Respir Med. 2013;107(2): 233-241. 
6. Miravitlles M, Murio C, Guerrero T, Gisbert R. Cost of chronic bronchitis and COPD. A 1-year follow-up study. Chest. 2003;123(3): 784-791.

7. Goldcopd.org [homepage on the internet]. Global strategy for the diagnosis, management and prevention of COPD, Global Initiative for Chronic Obstructive Lung Disease (GOLD). 2014. Available from: http://www.goldcopd.org. Accessed July 1, 2015.

8. Miravitlles M, Soler-Cataluña JJ, Calle M, et al. Spanish Guidelines for COPD (GesEPOC). Update 2014. Arch Bronconeumol. 2014; 50 (Suppl 1):1-16.

9. Ministry of Health, Equality and Social Policy [Anoro ${ }^{\circledR} 55 / 22 \mathrm{mcg}$ powder for inhalation]. Data Sheet. [database on the Internet]. Available from: http://www.aemps.gob.es/cima/fichasTecnicas. do?metodo=detalleForm. Spanish. Accessed July 1, 2015.

10. Catalá-López F, García-Altés A, Alvarez-Martín E, Gènova-Maleras R, Morant-Ginestar C, Parada A. Burden of disease and economic evaluation of healthcare interventions: are we investigating what really matters? BMC Health Serv Res. 2011;11:75.

11. Gonzalez-McQuire S, Tabberer M, Muellerova H, Briggs A, Lomas D, Rutten-van Mölken M. Development of a conceptual model for use in economic modeling of chronic obstructive pulmonary disease. Value Health. 2012;15(7):A470.

12. Lopez-Bastida J, Oliva J, Antoñanzas F, et al. [A proposed guideline for economic evaluation of health technologies]. Gac Sanit. 2010;24(2): 154-170. Spanish.

13. McGahn WF, Maiwenn AL, Doshi JA, Kamae I, Marx SE, Rindress D. The ISPOR good practice for quality improvement of cost-effectiveness research task force report. Value Health. 2009;12(8):1086-1099.

14. Vestbo J, Anderson W, Coxson HO, et al. Evaluation of COPD longitudinally to identify predictive surrogate end-points (ECLIPSE). Eur Respir J. 2008;31(4):869-873.

15. Agusti A, Calverley PM, Celli B, et al. Characterisation of COPD heterogeneity in the ECLIPSE cohort. Respir Res. 2010;11:122.

16. Exuzides A, Colby C, Briggs A, et al. Statistical modeling of disease progression for chronic obstructive pulmonary disease using data from the ECLIPSE Study. Med Decis Making. Epub 2015 Oct 8.

17. Rutten-van Mölken MP, Goossens LM. Cost effectiveness of pharmacological maintenance treatment for chronic obstructive pulmonary disease: a review of the evidence and methodological issues. Pharmacoeconomics. 2012;30(4):271-302.

18. IMS Heath databases [Medical dispensing database]. Total annual moving (MAT) April 2014-2015. Available from: http://www.imshealth. com. Accessed December 17, 2015.

19. Casanova C, Marin JM, Martinez-Gonzalez C, et al. New GOLD classification: longitudinal data on group assignment. Respir Res. 2014;15:3.

20. Almagro P, Martinez-Camblor P, Soriano JB, et al. Finding the best thresholds of FEV1 and dyspnea to predict 5-year survival in COPD patients: the COCOMICS study. PLoS One. 2014;9(2):e89866.

21. Ministry of Health, Equality and Social Policy [Spanish National Health Survey 2011-12]. [database on the Internet]. Available from: http://www.msssi.gob.es/estadEstudios/estadisticas/encuestaNacional/ encuesta2011.htm. Accessed July 1, 2015. Spanish.

22. Maleki-Yazdi MR, Kaelin T, Richard N, Zvarich M, Church A Efficacy and safety of umeclidinium/vilanterol $62.5 / 25 \mathrm{mcg}$ and tiotropium $18 \mathrm{mcg}$ in chronic obstructive pulmonary disease: results of a 24-week, randomized, controlled trial. Respir Med. 2014;108(12): 1752-1760.

23. Donohue JF, Niewoehner D, Brooks J, O’Dell D, Church A. Safety and tolerability of once-daily umeclidinium/vilanterol $125 / 25 \mathrm{mcg}$ and umeclidinium $125 \mathrm{mcg}$ in patients with chronic obstructive pulmonary disease: results from a 52-week, randomized, double-blind, placebocontrolled study. Respir Res. 2014,15:78.

24. Starkie HJ, Briggs AH, Chambers MG, Jones P. Predicting EQ-5D values using the SGRQ. Value Health. 2011;14(2):354-360.

25. Miravitlles M, Huerta A, Fernandez-Villar J. Generic utilities in chronic obstructive pulmonary disease patients stratified according to different staging systems. Health Qual Life Outcomes. 2014;12:120.
26. Miravitlles M, Huerta A, Valle M, et al. Clinical variables impacting on the estimation of utilities in chronic obstructive pulmonary disease. Int J Chron Obstruct Pulmon Dis. 2015;10:367-377.

27. Ministry of Health, Equality and Social Policy [Catalogue of sanitarian products included in the Spanish National Health System pharmaceutical provision]. April 2015. [database on the Internet]. Available from: http://www.msssi.gob.es/profesionales/nomenclator.do. Accessed July 1, 2015. Spanish.

28. Miravitlles M, Murio C, Guerrero T, Gisbert R; DAFNE Study Group. Pharmacoeconomic evaluation of acute exacerbations of chronic bronchitis and COPD. Chest. 2002;121(5):1449-1455.

29. Miravitlles M, Garcia-Polo C, Domenech A, Villegas G, Conget F, de la Roza C. Clinical outcomes and cost analysis of exacerbations in chronic obstructive pulmonary disease. Lung. 2013;191(5):523-530.

30. Punekar YS, Shukla A, Müllerova H. COPD management costs according to the frequency of COPD exacerbations in UK primary care. Int $J$ Chron Obstruct Pulmon Dis. 2014;9:65-73.

31. Sicras A, Huerta A, Navarro R, Ibañez J. [Use of resources and costs associated with the exacerbations of chronic obstructive pulmonary disease: a retrospective population-based study]. Semergen. 2014;40(4): 189-197. Spanish.

32. Briggs AH. Handling uncertainty in cost-effectiveness models. Pharmacoeconomics. 2000;17(5):479-500.

33. Decramer M, Anuzeto A, Kerwin E, et al. Efficacy and safety of umeclidinium plus vilanterol versus tiotropium, vilanterol, or umeclidinium monotherapy over 24 weeks in patients with chronic obstructive pulmonary disease: results from two multicenter, blinded, randomized controlled trials. Lancet Respir Med. 2014;2(6):472-486.

34. Sacristan JA, Oliva J, Del Llano J, Prieto L, Pinto JL. [What is an efficient health technology in Spain?]. Gac Sanit. 2002;16(4):334-343. Spanish.

35. De Cock E, Miravitlles M, Gonzalez-Juanatey JR, Azanza-Perea JR. [Threshold value of the cost per year of life gained to recommend the adoption of health technologies in Spain: evidence from a review] Pharmacoeconomics. 2007;4(3):97-107. Spanish.

36. De Lucas P, Miravitlles M, Rodriguez JM, de Miguel J, Lopez S, Sanchez G. [Cost-effectiveness analysis of tiotropium versus ipratropium in the treatment of COPD patients]. Pharmacoeconomics. 2004;1(3): 123-130. Spanish.

37. Rutten-van Mölken MP, Oostenbrink JB, Miravitlles M, Monz BU. Modelling the 5-year cost-effectiveness of tiotropium, salmeterol and ipratropium for the treatment of chronic obstructive pulmonary disease in Spain. Eur J Health Econ. 2007;8(2):123-135.

38. Brosa M, Diaz-Cerezo S, Miravitlles M. Gonzalez-Rojas N, Nieves D. [Cost-effectiveness analysis of tiotropium in the treatment of COPD in Spain]. Pharmacoeconomics. 2010;7(1):3-12. Spanish.

39. Brosa M, Perez-Alcantara F, Borderias-Clau L, Galdiz-Iturri JB, RieraFebrer M, Figueres-Sabate M. [Cost-utility anaysis of indacaterol versus tiotropium in the treatment of COPD in Spain]. Pharmacoeconomics 2013;10:89-97. Spanish.

40. Punekar YS, Roberts G, Ismaila A, O’Leay M. Cost-effectiveness of umeclidinium/vilanterol combination therapy among symptomatic COPD patients. Value Health. 2014;17(7):A595.

41. Price D, Keininger D, Costa-Scharplatz M, et al. Cost-effectiveness of the LAMA/LABA dual bronchodilator indacaterol/glycopirronium in a Swedish healthcare setting. Respir Med. 2014;108(12):1786-1793.

42. Hoogendoorn M, Feenstra TL, Asukai Y, et al. Cost-effectiveness models for chronic obstructive pulmonary disease: cross-model comparison of hypothetical treatment scenarios. Value Health. 2014;17(5): 525-536.

43. Calverley PM, Anderson JA, Celli B, et al. Salmeterol and fluticasone propionate and survival in chronic obstructive pulmonary disease. N Engl J Med. 2007;356(8):775-789.

44. Hurst JR, Vestbo J, Anzueto A, Locantore N, et al. Susceptibility to exacerbation in chronic obstructive pulmonary disease. $N$ Engl J Med. 2010;363(12):1128-1138. 


\section{Supplementary materials}

Table SI Risk equations developed for utility estimation

\begin{tabular}{lll}
\hline Risk equation & Scenario & Description \\
\hline MI & Base case & Saturated linear regression model \\
M2 & Sensitivity analysis & Reduction in number of variables according to goodness of fit index AIC \\
M3 & Sensitivity analysis & Grouping of frequency and severity of dyspnea: $\mathrm{mMRC2}$ (vs 0-I) and mMRC3-4 (vs 0-I) \\
M4 & Sensitivity analysis & Variable cough and sputum = score $\geq 2$ in first two items of CAT \\
M5 & Sensitivity analysis & Variable cough and sputum = score $\geq 4$ in first two items of CAT \\
\hline
\end{tabular}

Abbreviations: AIC, Akaike information criterion; mMRC, modified Medical Research Council; CAT, COPD Assessment Test.

Table S2 Variables considered in each of the risk equations

\begin{tabular}{|c|c|c|c|c|c|}
\hline & \multicolumn{5}{|c|}{ Base-case sensitivity analysis } \\
\hline & \multicolumn{5}{|l|}{ Effect } \\
\hline & MI & M2 & M3 & M4 & M5 \\
\hline Intercept & 0.8345 & 0.9158 & 0.8526 & 0.8345 & 0.8148 \\
\hline Female (vs male) & -0.0875 & -0.0902 & -0.0819 & -0.0875 & -0.0749 \\
\hline Low BMI (vs mean) & -0.0059 & - & -0.0870 & -0.0059 & -0.0153 \\
\hline High BMI (vs mean) & -0.0136 & - & -0.0305 & -0.0136 & -0.0197 \\
\hline Cardiovascular comorbidities (vs no) & -0.0074 & - & -0.0407 & -0.0074 & -0.0023 \\
\hline Other comorbidities (vs no) & -0.0074 & - & -0.0169 & -0.0074 & -0.0091 \\
\hline Smoker (vs ex-smoker) & -0.0244 & - & -0.0488 & -0.0244 & -0.0338 \\
\hline Age & 0.0012 & - & 0.0012 & 0.0012 & 0.0010 \\
\hline Number of exacerbations & -0.0291 & -0.0298 & -0.0338 & -0.0291 & -0.0316 \\
\hline $\mathrm{FEV}_{1}(\%)$ post-bronchodilator & 0.0006 & - & 0.0004 & 0.0006 & 0.0008 \\
\hline mMRC 2-3 (vs 0-1)a & -0.1541 & -0.1606 & -0.1089 & -0.1541 & -0.1573 \\
\hline mMRC $4(\text { vs } 0-I)^{a}$ & -0.5326 & -0.5390 & $-0.304 I$ & -0.5326 & -0.5275 \\
\hline Cough and sputum (vs no) ${ }^{b}$ & -0.0672 & -0.0581 & -0.0600 & -0.0672 & -0.0776 \\
\hline
\end{tabular}

Notes: an M3, grouping is mMRC 2 (vs 0-I) and mMRC 3-4 (vs 0-I). bln M4 and M5, cough and sputum are considered as equivalent to the score in the first two items of CAT $\geq 2$ and $\geq 4$, respectively.

Abbreviations: BMI, body mass index; $\mathrm{FEV}_{1}$, forced expiratory volume in I second; mMRC, modified Medical Research Council; -, variable not considered in the model.

Table S3 Results obtained considering risk equations developed for utility estimation

\begin{tabular}{|c|c|c|c|c|c|c|c|}
\hline & \multicolumn{2}{|c|}{ UMEC/VI } & \multicolumn{2}{|l|}{ TIO } & \multicolumn{3}{|c|}{ UMEC/VI vs TIO } \\
\hline & QALY & Cost $(€)$ & QALY & Cost $(€)$ & $\triangle Q A L Y$ & $\Delta \operatorname{Cost}(€)$ & ICER (€/QALY) \\
\hline \multicolumn{8}{|c|}{ Base case } \\
\hline MI & 2.025 & 6,215 & 1.998 & 5,625 & +0.0275 & +590.1 & 21,475 \\
\hline M2 & 2.043 & 6,215 & 2.039 & 5,625 & +0.0048 & +590.1 & 123,425 \\
\hline M3 & 2.021 & 6,215 & 1.994 & 5,625 & +0.0271 & +590.1 & 21,794 \\
\hline M4 & 2.028 & 6,215 & 1.999 & 5,625 & +0.0288 & +590.1 & 20,456 \\
\hline M5 & 2.024 & 6,215 & 1.997 & 5,625 & +0.0271 & +590.1 & 21,759 \\
\hline
\end{tabular}

Abbreviations: UMEC/VI, umeclidinium and vilanterol; TIO, tiotropium; QALY, quality-adjusted life years; ICER, incremental cost-effectiveness ratio.

International Journal of COPD

\section{Publish your work in this journal}

The International Journal of COPD is an international, peer-reviewed journal of therapeutics and pharmacology focusing on concise rapid reporting of clinical studies and reviews in COPD. Special focus is given to the pathophysiological processes underlying the disease, intervention programs, patient focused education, and self management protocols.

\section{Dovepress}

This journal is indexed on PubMed Central, MedLine and CAS. The manuscript management system is completely online and includes a very quick and fair peer-review system, which is all easy to use. Visit $\mathrm{http}: / /$ www.dovepress.com/testimonials.php to read real quotes from published authors. 